\title{
Diagnosing malabsorption in the intensive care unit
}

\section{Martijn B Keur, Albertus Beishuizen and Adriaan A van Bodegraven*}

\author{
Address: Departments of Intensive Care and Gastroenterology, VU University Medical Center Amsterdam, De Boelelaan 1117, \\ 1081 HV Amsterdam, The Netherlands \\ *Corresponding author: Adriaan A van Bodegraven (v.bodegraven@vumc.nl) \\ FI000 Medicine Reports 2010, 2:7 (doi:10.34I0/M2-7)
}

The electronic version of this article is the complete one and can be found at: http://fl000.com/reports/medicine/content/2/7

\begin{abstract}
Malabsorption as a result of decreased intestinal function is a frequently occurring problem in intensive care units. Small bowel dysfunction may lead to malnutrition and may predispose patients to infectious complications (sepsis) and may be linked to increased hospitalization duration, morbidity and mortality. There are several small bowel function tests, such as faecal fat excretion and sugar absorption tests, but data specifically applicable to the intensive care setting are limited. Moreover, there are multiple confounders such as altered intestinal permeability, changed transit time and renal dysfunction. A more specific test, fasting plasma citrulline concentration, has poor test characteristics for detection of decreased intestinal function in patients with dysfunctional enterocytes. Therefore, a citrulline generation test was recently developed in order to measure the conversion of glutamine (administered either enterally or intravenously) into citrulline. This conversion takes place exclusively in a properly functioning enterocyte; therefore, citrulline generation upon glutamine stimulation may be a promising biomarker for assessment of the small bowel function.
\end{abstract}

\section{Introduction and context}

Malabsorption in intensive care unit (ICU) patients is arbitrarily defined as an intestinal absorption capacity of $85 \%$ or less. It is believed to be a frequently occurring problem in ICUs, particularly in patients suffering from sepsis or multiple organ dysfunction [1,2]. Malabsorption is the most important clinical sign of intestinal dysfunction or failure, reflecting various altered aspects of intestinal physiology due to a diseased state. Some of these altered aspects are coordinated intestinal transport (motility) and coordinated exocrine digestive functions of various organs like the pancreas, liver and jejunum (enterocytes). Other factors involve the intestinal wall function, like mucosal immunological response and intestinal barrier function, as well as visceral blood flow. Critically ill patients may be prone to a reduced enterocyte function due mainly to a reduced splanchnic blood flow. This dysfunction may subsequently contribute to (the alleged) bacterial translocation and ultimately sepsis and multi-organ dysfunction syndrome (MODS) $[3,4]$. Simple, clear-cut and validated tests to assess these various aspects of coordinated physiological functions of digestion are not available at the bedside. Nevertheless, adequate absorption of food is paramount to the improvement of the patient's condition and to the outcome of the critically ill patient [5]. This concise review aims to emphasize the importance of diagnosing malabsorption and to give new insights into how to assess intestinal function.

\section{Current tests}

In critically ill patients, it may be cumbersome to assess the various aspects of digestion as there are no validated tests to quantify the small bowel function. To meet this challenge, we tend to approach the problem as a failure of the intestinal tract comparable with other organ failures as a part of MODS (such as renal failure). However, a simple blood test or marker such as creatinine or BUN (blood urea nitrogen) levels is lacking in the evaluation of intestinal function. Thus, secondary variables, such as measurement of intestinal barrier function and intestinal absorption, are usually applied. Relatively 
common small bowel function tests are the sugar absorption test (SAT), quantification of fat excretion in stools (FES) and bomb calorimetry (BC).

\section{Sugar absorption test}

Gastrointestinal permeability can be measured by the SAT. During this test, a solution of multiple saccharides is orally administered [6-8]. The applied saccharides have different molecule sizes and are specifically chosen as these cannot be metabolized in the human body. The tight junctions in the tip of the villi allow translocation of small saccharides, whereas translocation of larger saccharides is restricted to the crypts [6]. In a normally functioning small bowel, the permeability for small saccharides is higher than for larger saccharides. However, under pathological conditions, the permeability for small saccharides decreases whereas the permeability for larger saccharides increases [7]. The amount of renallyexcreted saccharides (particularly the large saccharide/ small saccharide ratio) is an indicator of small bowel absorptive function $[7,8]$. There are some flaws in this test. By means of SAT, intestinal (paracellular) permeability rather than (metabolic) enterocyte function is assessed [7]. In addition, Oudemans-van Straaten et al. [9] reported that the SAT is unreliable when used on ICU patients with multiple organ failure because there are various non-permeability-related confounders, such as impaired renal function and diminished intestinal motility. Also, oliguria/anuria limits its use in daily ICU practice.

\section{Quantification of fat excretion in stools}

This test aims to quantify the FES. The patient is given a diet containing a known high amount of fat to saturate the intestinal mechanisms and to challenge the intestinal maximal absorptive capacity. During this diet, the patient's faeces are sampled for 24 hours or, preferably, 72 hours. The amount of faecal fat can be measured by the Van de Kamer method, which allows the calculation of fat absorption capacity [10]. The underlying concept of FES is that malabsorption of fat correlates with malabsorption in general. However, Wierdsma and van Bodegraven [11] found that not all malabsorption states are detected by measuring fat in faeces. Faecal carbohydrate loss significantly contributed to the malnutrition state, and this contribution is overlooked by looking merely at FES [11].

\section{Bomb calorimetry}

Faecal energy is measured by combustion of a faecal sample and subsequent calculation of 72 hours of faecal energy loss, which is considered the (alleged) gold standard for intestinal digestive function $[12,13]$. Combining the energy (caloric) intake and the faecal energy loss into a formula allows the calculation of intestinal energy absorption (percentage). Again, data are scarce, specifically in the critically ill, in whom BC is hampered by problems with reliable collection of faeces during a full 3-day period [1].

\section{Recent advances}

Citrulline is an amino acid that is produced almost entirely from glutamine in the enterocytes. Because this conversion can take place only in a functioning enterocyte, citrulline has been proposed as an attractive and promising biomarker to assess the function of the small intestine $[14,15]$. Previous studies reported the value of fasting plasma citrulline concentration as a biomarker for enterocyte (intestinal) mass in a wide array of intestinal diseases such as coeliac disease, Crohn's disease, short bowel syndrome and radiation enteritis, and in recipients of intestinal transplants [16-21]. Recently, however, fasting plasma citrulline concentration was found to be a poor predictor of the clinical relevance of decreased intestinal function in patients with short bowel syndrome and, in other words, failed to predict long-term dependence on total parenteral nutrition $[22,23]$.

\section{Citrulline generation test}

The citrulline generation test (CGT) is a recently developed test to dynamically measure the conversion of glutamine into citrulline over time, following administration of glutamine as a dipeptide with alanine (Dipeptiven). Through the administration of a large quantity of glutamine-alanine, the capacity of this enterocytic metabolic pathway is challenged, and this challenge is manifested by a decreased conversion in patients with a decreased enterocyte mass. The CGT is validated in various intestinal diseases [14]. In practice, following a slow intravenous injection of $100 \mathrm{~mL}$ of glutamine-alanine, multiple blood samples are drawn at different times to determine the increment (in other words, generation) in serum level of citrulline by using reverse-phase high-performance liquid chromatography [24]. The CGT is easily applied in patients with suspected small bowel dysfunction. The citrulline generation [as defined by either the citrulline increase or the AUC (area under the curve)] correlates closely with enterocyte mass and enterocyte function and reflects the amount of functioning enterocytes to generate citrulline. In stable ICU patients, preliminary results from our own group indicate a reduced enterocyte mass that was associated with disease severity.

\section{Implications for clinical practice}

The small intestine has many functions, two of which are of major importance in the setting of critical illness: nutrient and energy absorption and function of the 
intestinal barrier against antigens. The absorption of nutrients, water and drugs is an essential part of improving or regaining health [5]. Malnutrition and insufficient bioavailability of drugs can increase hospitalization stay, morbidity, mortality and costs [5]. The intestinal barrier function is a very important intestinal feature that keeps bacteria from translocating into the blood and thus prevents sepsis from originating from the gut $[3,4]$.

It is obvious that dysfunction of the small intestine may have serious consequences and that identifying those patients who are at risk for developing malabsorption or those who are already malnourished is therefore pivotal. The most common applied intestinal function tests faecal, urine and blood tests alike - all have several major flaws (in particular in very ill patients), which prevent these tests from being used and render it very difficult to accurately quantify intestinal function in the ICU setting.

The CGT, a more functional test, measures the enterocyte function and is likely to play an important role in the assessment of intestinal function in the future. The CGT is relatively easy to perform but warrants further validation in several ICU patient cohorts by comparing it with one or more of the other small bowel function tests and by taking nutritional status into account.

\section{Abbreviations}

BC, bomb calorimetry; BUN, blood urea nitrogen; CGT, citrulline generation test; FES, fat excretion in stools; ICU, intensive care unit; MODS, multi-organ dysfunction syndrome; SAT, sugar absorption test.

\section{Competing interests}

The authors declare that they have no competing interests.

\section{References}

I. Strack van Schijndel RJ, Wierdsma NJ, van Heijningen EM, Weijs PJ, de Groot SD, Girbes AR: Fecal energy losses in enterally fed intensive care patients: an explorative study using bomb calorimetry. Am J Gastroenterol 2007, 102: I-6.

2. Carlson GL: Surgical management of intestinal failure. Proc Nutr Soc 2003, 62:71I-8.

3. Doig C], Sutherland LR, Sandham JD, Fick GH, Verhoef M, Meddings JB: Increased intestinal permeability is associated with the development of multiple organ dysfunction syndrome in critically ill ICU patients. Am J Respir Crit Care Med I998, I 58:444-5I.

4. Deitch EA: Multiple organ failure: pathophysiology and potential future therapy. Ann Surg 1992, 216:117-34.

5. Martindale RG, McClave SA, Vanek VW, McCarthy M, Roberts P, Taylor B, Ochoa JB, Napolitano L, Cresci G; American College of Critical Care Medicine; A.S.P.E.N. Board of Directors: Guidelines for the provision and assessment of nutrition support therapy in the adult critically ill patient: Society of Critical Care Medicine and American Society for Parenteral and Enteral Nutrition: Executive Summary. Crit Care Med 2009, 37:1757-6I.
6. Bjarnason I, MacPherson A, Hollander D: Intestinal permeability: an overview. Gastroenterology 1995, 108:1566-8I.

7. van Elburg RM, Uil JJ, Kokke FT, Mulder AM, van de Broek WG, Mulder CJ, Heymans HS: Repeatability of the sugar-absorption test, using lactulose and mannitol, for measuring intestinal permeability for sugars. J Pediatr Gastroenterol Nutr 1995, 20: 184-8.

8. Hessels J, Eidhof HH, Steggink J, Roeloffzen WW, Wu K, Tan G, van de Stadt J, van Bergeijk L: Assessment of hypolactasia and sitespecific intestinal permeability by differential sugar absorption of raffinose, lactose, sucrose and mannitol. Clin Chem Lab Med 2003, 4I: 1056-63.

9. Oudemans-van Straaten HM, van der Voort PJ, Hoek FJ, Bosman RJ, van der Spoel Jl, Zandstra DF: Pitfalls in gastrointestinal permeability measurement in ICU patients with multiple organ failure using differential sugar absorption. Intensive Care Med 2002, 28: $130-8$.

10. Van de Kamer JH, Ten Bokkel Huinink H, Weyers HA: Rapid method for determination of fat in feces. J Biol Chem 1949, 177:347-55.

II. Wierdsma NJ, van Bodegraven AA: Energy losses from a short bowel: not only fat. Ned Tijdschr Geneeskd 2005, 149:38I-4.

12. Miller DS, Payne PR: A ballistic bomb calorimeter. Br J Nutr 1959, 13:50|-8.

13. Lovelady HG, Stork E): An improved method for preparation of feces for bomb calorimetry. Clin Chem 1970, 16:253-4.

14. Peters JHC, Wierdsma NJ, Teerlink T, van Leeuwen PAM, Mulder CJJ, van Bodegraven AA: The citrulline generation test: proposal for a new enterocyte function test. Aliment Pharmacol Ther 2008, 27:1300-10.

15. Crenn P, Messing B, Cynober L: Citrulline as a biomarker of intestinal failure due to enterocyte mass reduction. Clin Nutr 2008, 27:328-39.

16. Crenn P, Vahedi K, Lavergne-Slove A, Cynober L, Matuchansky C, Messing B: Plasma citrulline: a marker of enterocyte mass in villous atrophy-associated small bowel disease. Gastroenterology 2003, 124:1210-9.

17. Miceli E, Poggi N, Missanelli A, Bianchi P, Moratti R, Corazza GR: Is serum citrulline measurement clinically useful in coeliac disease? Intern Emerg Med 2008, 3:233-6.

18. Rhoads JM, Plunkett E, Galanko J, Lichtman S, Taylor L, Maynor A, Weiner T, Freeman K, Guarisco JL, Wu GY: Serum citrulline levels correlate with enteral tolerance and bowel length in infants with short bowel syndrome. J Pediatr 2005, 146:542-7.

19. Lutgens LC, Blijlevens NM, Deutz NE, Donnelly JP, Lambin P, de Pauw BE: Monitoring myeloablative therapy-induced small bowel toxicity by serum citrulline concentration: a comparison with sugar permeability tests. Cancer 2005, 103:191-9.

20. Papadia C, Sherwood RA, Kalantzis C, Wallis K, Volta U, Fiorini E, Forbes A: Plasma citrulline concentration: a reliable marker of small bowel absorptive capacity independent of intestinal inflammation. Am J Gastroenterol 2007, 102:1474-82.

21. Pappas PA, Saudubray JM, Tzakis AG, Rabier D, Carreno MR, GomezMarin O, Huijing F, Gelman B, Levi DM, Nery JR, Kato T, Mittal N, Nishida S, Thompson JF, Ruiz P: Serum citrulline as a marker of acute cellular rejection for intestinal transplantation. Transplant Proc 2002, 34:915-7.

22. Peters JHC, Wierdsma NJ, Teerlink T, van Leeuwen PAM, Mulder CJJ, van Bodegraven AA: Poor diagnostic accuracy of a single fasting plasma citrulline concentration to assess intestinal energy absorption capacity. Am J Gastroenterol 2007, 102:28I4-9.

23. Luo M, Fernández-Estívariz C, Manatunga AK, Bazargan N, Gu LH, Jones DP, Klapproth JM, Sitaraman SV, Leader LM, Galloway JR, Ziegler TR: Are plasma citrulline and glutamine biomarkers of intestinal absorptive function in patients with short bowel syndrome? J Parenter Enteral Nutr 2007, 3 I: I-7.

24. Teerlink T, van Leeuwen PA, Houdijk A: Plasma amino acids determined by liquid chromatography within $\mathbf{I}$ minutes. Clin Chem 1994, 40/2:245-9. 